\title{
Epidural Hematoma Treated Conservatively: When to Expect the Worst
}

\author{
Mohammed Basamh, Antony Robert, Julie Lamoureux, Rajeet Singh Saluja, \\ Judith Marcoux
}

\begin{abstract}
Background: The Brain Trauma Foundation's 2006 surgical guidelines have objectively defined the epidural hematoma $(\mathrm{EDH})$ patients who can be treated conservatively. Since then, the literature has not provided adequate clues to identify patients who are at higher risk for EDH progression (EDHP) and conversion to surgical therapy. The goal of our study was to identify those patients. Methods: We carried a retrospective review over a 5-year period of all EDH who were initially triaged for conservative management. Demographic data, injury severity and history, neurological status, use of anticoagulants or anti-platelets, radiological parameters, conversion to surgery and its timing, and Glasgow Outcome Scale were analyzed. Bivariate association and further logistic regression were used to point out the significant predictors of EDHP and conversion to surgery. Results: 125 patients (75\% of all EDH) were included. The mean age was 39.1 years. The brain injury was mild in $62.4 \%$ of our sample and severe in $14.4 \%$. Only $11.2 \%$ of the patients required surgery. Statistical comparison showed that younger age $(\mathrm{p}<0.0001)$ and coagulopathy $(\mathrm{p}=0.009)$ were the only significant factors for conversion to surgery. There was no difference in outcomes between patients who had EDHP and those who did not. Conclusions: Most traumatic EDH are not surgical at presentation. The rate of conversion to surgery is low. Significant predictors of EDHP are coagulopathy and younger age. These patients need closer observation because of a higher risk of EDHP. Outcome of surgical conversion was similar to successful conservative management.
\end{abstract}

RÉSUMÉ: Hématome épidural traité de façon conservatrice : quand s'attendre au pire. Contexte : Les lignes directrices chirurgicales de la Brain Trauma Foundation de 2006 ont défini objectivement les patients atteints d'un hématome épidural (HÉD) qui peuvent être traités de façon conservatrice. Depuis lors, il n'existe pas dans la littérature d'indices adéquats pour identifier les patients qui sont à plus haut risque de progression de l'HÉD et chez qui un traitement chirurgical doit être envisagé. Le but de notre étude était d'identifier ces patients. Méthode : Nous avons effectué une revue rétrospective sur une période de 5 ans des dossiers de tous les patients atteints d'un HÉD qui ont été assignés initialement au traitement conservateur. Nous avons analysé les données démographiques, la sévérité de la lésion et son historique, l'état neurologique, la prise d'anticoagulants ou d'antiplaquettaires, les paramètres radiologiques, le recours à un traitement chirurgical et le moment où il a été réalisé ainsi que le score au Glasgow Outcome Scale. L'analyse bivariée ainsi que l'analyse de régression logistique ont été utilisées pour déterminer les facteurs de prédiction significatifs de la progression de l'HÉD et du recours à la chirurgie. Résultats : Cent vingt-cinq patients (75\% des patients atteints d'un HÉD) ont été inclus dans l'étude. L'âge moyen des patients était de 39,1 ans. La lésion cérébrale était légère chez $62,4 \%$ des patients alors qu'elle était sévère chez 14,4\% d'entre eux. Seulement 11,2\% des patients ont nécessité une chirurgie. L'analyse statistique a montré que le jeune âge du patient (p 0,0001) et la présence d'une coagulopathie $(p=0,009)$ étaient les seuls facteurs significatifs du recours à la chirurgie. Il n'existait pas de différence entre les résultats chez les patients qui avaient eu une progression de l'HÉD et ceux des patients qui n'en avaient pas eu. Conclusions : La plupart des HÉD traumatiques ne requièrent pas de traitement chirurgical initialement. Le taux de recours éventuel à la chirurgie est bas. Les facteurs de prédiction significatifs de la progression de l'HÉD sont la présence d'une coagulopathie et le jeune âge du patient. Ces patients doivent être observés de près car ils sont à risque plus élevé de progression de l'HÉD. Le résultat du recours à la chirurgie était similaire à celui du traitement conservateur lorsque celui-ci était efficace.

Keywords: Traumatic brain injury, epidural hematoma, non-surgical treatment, injury progression

doi:10.1017/cjn.2015.232

Can J Neurol Sci. 2016; 43: 74-81

Epidural hematomas $(\mathrm{EDH})$ represent $2.7-4 \%$ of traumatic brain injuries $(\mathrm{TBI})^{1-3}$ and have a peak incidence during the second life decade. ${ }^{1,4-8}$ The source of bleeding can be an injured middle meningeal artery, diploic vein or venous sinus. ${ }^{1}$ The Brain Trauma Foundation (BTF) surgical guidelines, although based on class III studies, are widely accepted. They provide objective criteria for deciding either surgical or conservative management in
From the Division of Neurosurgery (MB), King Abdulaziz University Hospital, Jeddah, Saudi Arabia; Emergency Medicine (AR), McGill University; Department of Neurosurgery (RSS, JM), Montreal General Hospital, McGill University Health Centre, Montreal, Quebec, Canada; Baptist Health South Florida (JL), Miami, Florida, USA. Received August 3, 2014. Final Revisions Submitted January 15, 2015. Correspondence to: Judith Marcoux, Assistant Professor, Department of Neurosurgery, Montreal General Hospital, McGill University Health Centre, 1650 Cedar ave, room L7-516, Montreal, Quebec, Canada, H3G 1A4. Email: judith.marcoux@mcgill.ca 
EDH patients. ${ }^{1}$ Yet those who are managed non-operatively remain a concern for the treating neurosurgeon as EDH progression (EDHP) may alter the course of conservative approach. Incidence of EDHP needing surgical intervention is reported to range between $6.25-32 \%$ of EDH patients treated initially conservatively in larger studies adopting BTF guidelines or, before its publication, studies that had more stringent criteria for conservative approach. ${ }^{9-12}$ One study had $23 \%$ EDHP in the sample but only $10 \%$ required evacuation. ${ }^{12}$ Another study had $32 \%$ of its conservative group (59 patients) complicated with EDHP and $22 \%$ of them required surgical intervention. ${ }^{10}$ The other authors had to operate on a single EDHP case each. ${ }^{9,11}$ Epidural hematoma progression represented $7.9 \%$ of all cases of TBI progression in a randomized controlled trial. ${ }^{13}$ The risk factors of such progression are still not very obvious and the literature has seldom addressed this issue with specific attention and mostly in studies prior to the publication of the BTF surgical guidelines. We carried out this study to identify which patients, among those candidates with $\mathrm{EDH}$, suitable for an initial non-operative treatment, are at greater risk of EDHP, and to determine when they become surgical candidates.

\section{Methods}

\section{Patient population}

The current study is a Case-Control study in which we retrospectively reviewed the charts of TBI patients who were admitted, over a five-year period, to the Montreal General Hospital, a level 1 trauma center, and one of only three adult level 1 trauma centers serving the province of Quebec, Canada, which has a population of almost eight million people. Nearly 2800 patients were admitted with a diagnosis of TBI during that five-year period. The Montreal General Hospital Traumatic Brain Injury Database and the Trauma Registry Database were used to identify all patients admitted between January 1st, 2006 and December 31st, 2010 with a diagnosis of traumatic EDH. Our inclusion criteria were: all patients with a traumatic EDH, with or without other brain injury types, for whom conservative management approach was planned initially. Those who had cranial surgery for a lesion other than EDH on the opposite side were included. Patients who were admitted for urgent surgery, those who were deemed non salvageable at presentation, or those for whom the initial (CT) images were acquired at another institution and were not available for review were excluded. Patients for whom charts were incomplete were also excluded.

\section{Patient management}

All patients with a traumatic EDH were evaluated by a dedicated trauma team and by the neurosurgery service. Patients requiring immediate surgery were directed to the operating room. The study spans a time period shortly before the publication and application of the BTF surgical guidelines. Therefore the decision to operate immediately, versus conservative management, was left to the treating neurosurgeon. Patients with small $\operatorname{EDH}\left(<30 \mathrm{~cm}^{3}\right)$ and no associated midline shift or deficit were initially conservatively treated. They were observed in the emergency department or in the intensive care unit under close monitoring for at least 24 hours. The CT scans were routinely done upon presentation then routinely repeated within 6-12 hours and whenever neurological deterioration occurred. Patients who were admitted to the intensive care unit underwent a second routine follow-up CT scan after 48 hours if venous thrombo-prophylaxis was to be initiated.

\section{Data collection}

The charts were reviewed for demographic data, TBI severity using Glasgow Coma Scale (GCS), global injury severity using the Injury Severity Score (ISS), method of injury, neurological status at presentation, use of anticoagulants or anti-platelet medications, presence of alcohol intoxication or coagulopathy, defined as an International Randomized ratio (INR) $>1.2$, or a partial thromboplastin time (PTT) $>50$ seconds for the first 24 hours following admission. The CT scans were reviewed to retrieve EDH site and parameters, note any mass effect or other cranial injuries and measure the midline shift (MLS). The size of the lesions was collected in three dimensions. The width was measured as the transverse diameter, the length as antero-posterior diameter and the depth as the supero-inferior diameter. For use in the regressions, we computed an approximated volume by multiplying the three dimensions using the equation: volume = $\mathrm{ABC} / 2 .{ }^{14}$ The time delay between the initial CT and the follow up CT was also recorded

\section{Outcome measures}

The primary outcome measures were: (1) the percentage of patients initially treated conservatively who required eventual surgical evacuation of their $\mathrm{EDH}$; (2) the timing for that delayed surgery; (3) the reason for requiring this delayed surgical evacuation; (4) the method used for surgical evacuation. Secondary outcome measure was the extended Glasgow Outcome Scale (GOSE) score ${ }^{15-16}$ at discharge from the acute care hospital, whether the discharge destination was home or another medical facility. The GOSE was always assigned according to a consensus within the multidisciplinary team at discharge from the acute care hospital.

\section{Statistics}

The patients were categorized into two groups: "observation" group with successful conservative approach and "EDHP" group that required urgent surgical evacuation. After statistically comparing both groups' characteristics, Bivariate Association statistical analysis was used to associate risk factors with EDHP. A logistic regression was run to predict the occurrence of EDPH and subsequent surgery. Subsequently, a stepwise logistic regression $\left(\mathrm{p}_{\text {in }}<0.05\right)$ was used and the significantly different variables were entered in the model. Outcomes were assessed by linear and bivariate regressions using the GOSE scale.

\section{RESULTS}

\section{The need for surgical evacuation}

A total of 201 patients with a diagnosis of EDH were retrieved from our center's TBI registry. Of those, 30 were excluded because they had been wrongly labelled as EDH, and five were excluded because only comfort measures were offered (two patients), or the data were incomplete (three patients). Therefore, 166 patients had a diagnosis of traumatic EDH and were actively treated. Of those, 41 required emergency evacuation (24.7\%) and 125 patients $(75.3 \%)$ were initially observed and were therefore 


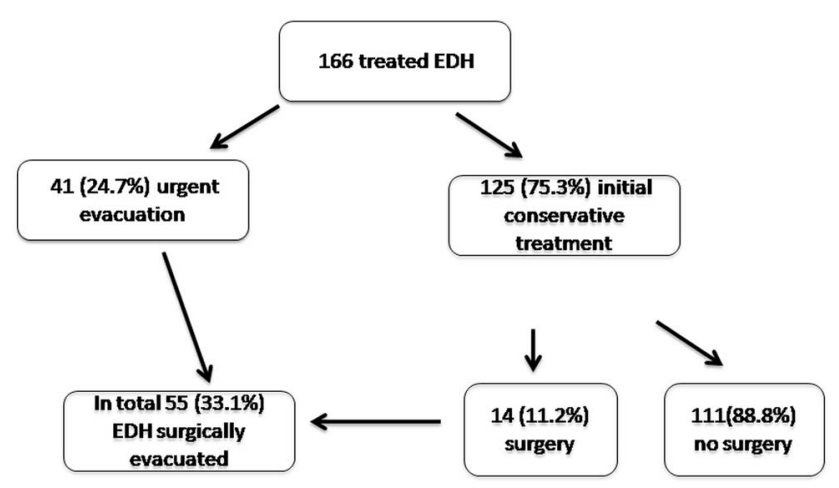

Figure 1: Distribution of all treated epidural hematoma between immediate surgical treatment, initial conservative treatment and failed conservative treatment.

included in the present study. The majority (111 patients or $88.8 \%$ ) of the patients with EDH who were initially observed remained non-operative, and only 14 patients $(11.2 \%)$ required delayed surgery. Therefore, of all the patients with traumatic EDH actively treated, 55 eventually required surgical evacuation of the EDH (33.1\%). Figure 1 illustrates the organisation of the sample.

\section{Demographic data (age, GCS, ISS, mechanism of injury, alcohol intoxication)}

The mean age in the entire sample was $39.1+/-18.0$ years of age (range 16-96). Figure 2 depicts the age distribution of the sample. Three patients had bilateral EDH. In order to avoid having dependence in the sample, only one lesion was chosen randomly in those patients. Men composed the majority of the sample (81.6\%). Glasgow Coma Score at admission varied between 3 and 15 with a mean $( \pm$ SD) of $12.6 \pm 3.4$ and a median of 14 . The majority of the sample $(62.4 \%)$ had a mild TBI (GCS after resuscitation between 13 and 15), and $14.4 \%$ had a severe TBI (GCS 3-8). The average ( \pm SD) ISS score was 27.5 \pm 8.6 . Sixty-one percent of the sample experienced a loss of consciousness at the time of the trauma. Among those who did not experience loss of consciousness, $23.4 \%$ experienced amnesia. The most frequent mechanisms of injury were fall from height (27.9\%) and assault $(20.5 \%)$. Table 1 gives the relative incidence of each mechanism of injury. Of the 115 patients who have been tested, $40.9 \%$ tested positive for blood ethanol.

\section{Coagulation}

Of the 108 patients who had the information in their chart, $3.7 \%$ were using anti-platelets or anticoagulants but none of them was among the EDHP group. Of the 114 patients whose coagulation profiles were tested, $19.3 \%$ had coagulation abnormalities.

\section{EDH site and size}

A little more than half $(56.4 \%)$ had a right sided lesion. Almost half of the lesions were temporal $(48.0 \%$ ) (see Table 2 for location distribution). The mean $( \pm \mathrm{SD})$ width, length, depth and volume were $10.2( \pm 11.4) \mathrm{mm}, 30.7( \pm 15.5) \mathrm{mm}, 26.2( \pm 18.2) \mathrm{mm}$ and $9.788 .7( \pm 15.390 .1) \mathrm{cm}^{3}$ respectively. More than $93 \%$ of the sample had less than $2 \mathrm{~mm}$ MLS. A large majority of the patients

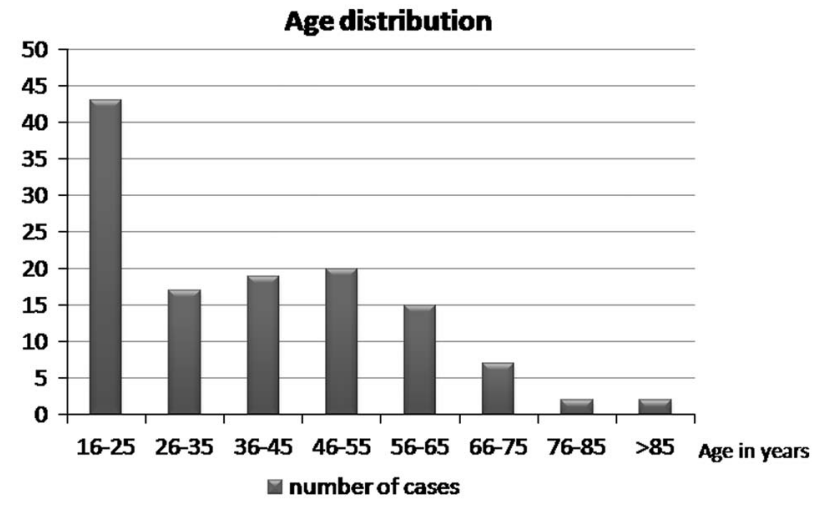

Figure 2: Distribution of age in the sample.

(72.0\%) had related fractures but only $5.6 \%$ were depressed fractures.

\section{Detection of EDHP}

All of the EDHP patients needed evacuation. Five patients had EDHP detected because they showed signs of neurological deterioration and a CT was repeated urgently. However, EDHP was detected by routine follow up CTs in most of those with mild TBI (six out of eight patients) and half of those with moderate (two of four) and severe (one of two) TBI. The initial volume of EDH that eventually progressed was $13 \mathrm{~cm}^{3}$ on average, while the volume at progression was $21 \mathrm{~cm}^{3}$. Time delay for EDHP occurrence ranged between 5-30 hours (h) from the initial CT, with a mean time of $12.4 \mathrm{~h}$. Two patients had a $30 \mathrm{~h}$ time interval for the EDHP to progress. One of those two actually sought medical attention only two days after the trauma. Hence the progression of $\mathrm{EDH}$ in that case was much delayed.

\section{Bivariate associations between patient and trauma characteristics and surgery event}

The EDHP group who had surgery was significantly younger than the other group $(\mathrm{p}<0.0001)$. Among the non-operated patients, 16 out of the 101 tested for coagulation had abnormalities detected (16.7\%). This was significantly higher in the EDHP group where 6 of the 13 tested patients $(46.1 \%)$ had documented coagulation abnormality $(\mathrm{p}=0.009)$.

There were no differences in gender, ISS scores, GCS scores, proportion of loss of consciousness, mechanism of trauma,

Table 1: Frequency of mechanism of trauma $(n=122)$

\begin{tabular}{l|c|c}
\hline Mechanism & Frequency & Percent \\
\hline FFH & 34 & 27.87 \\
\hline MVA & 21 & 17.21 \\
\hline Assault & 25 & 20.49 \\
\hline Bike & 15 & 12.30 \\
\hline FFOH & 13 & 10.66 \\
\hline Ped vs car & 14 & 11.48 \\
\hline
\end{tabular}

FFH: Fall from height, MVA: Motor vehicle accident, FFOH: Fall from own height, ped vs car: pedestrian versus car 
Table 2: Epidural hematoma location distribution $(n=125)$

\begin{tabular}{l|c|c}
\hline Location & Frequency & Percent \\
\hline Frontal & 39 & 31.2 \\
\hline Temporal & 60 & 48 \\
\hline Parietal & 15 & 12 \\
\hline Post. fossa & 2 & 1.6 \\
\hline Occipital & 9 & 7.20 \\
\hline
\end{tabular}

Post. fossa $=$ posterior fossa

proportion of presence of alcohol in the blood, proportion of use of anticoagulant or anti-platelet therapy, side of the lesion, location of the lesion, midline shift, proportion of associated fractures, proportion of depressed fractures, any of the dimensions of size or volume of the lesion between the EDHP and non-surgical groups.
Table 3 lists all the variables, the statistical test used to compare them and the $\mathrm{p}$ values for each.

\section{Prediction model for EDHP}

Age was entered as a control variable since the groups had different mean ages. Increasing age decreases the odds of having surgery (odds ratio $(\mathrm{OR})=0.94 ; 95 \%$ confidence interval $(\mathrm{CI})$ $=[0.91 ; 0.97])$. After controlling for age, having a coagulation abnormality increased the odds of having surgery by an average of 6 times $(\mathrm{OR}=6.12,95 \% \mathrm{CI}=[1.54 ; 24.36])$ but the volume of the lesion was an insignificant predictor. Table 4 shows the exponentiated coefficients (OR) for each variable in the model as well as their significance.

Figure 3 shows the ROC curve of this regression model. The area under the curve is 0.813 and is significantly larger than 0.5 , indicating those variables are important predictors of the occurrence of surgery. A sensitivity/specificity plot as in Figure 4 shows that when the probability of surgery is larger than $12.5 \%$

Table 3: Statistical comparison of surgery v. no surgery groups

\begin{tabular}{|c|c|c|c|}
\hline Variable & Surgery $(n=14)$ & No surgery $(n=111)$ & Test and significance \\
\hline Age $($ mean \pm SD) $($ years $)$ & $26.93 \pm 7.72$ & $40.61 \pm 18.37$ & $\mathrm{t}_{(36.01 \mathrm{df})}=5.0658, \mathbf{p}<\mathbf{0 . 0 0 0 1} *$ \\
\hline Gender (\% males) & $92.9 \%$ & $80.2 \%$ & $\chi_{1 \mathrm{df}}^{2}=1.331, \mathrm{p}=0.249$ \\
\hline ISS $($ Mean \pm SD) & $30.43 \pm 8.43$ & $27.13 \pm 8.58$ & $\mathrm{t}(123)=1.359, \mathrm{p}=0.176$ \\
\hline GCS & $12.36 \pm 3.39$ & $12.65 \pm 3.38$ & $\mathrm{z}(\mathrm{MW})=0.041, \mathrm{p}=0.967$ \\
\hline LOC (\% yes) & $57.14 \%$ & $61.47 \%$ & $\chi_{2 \mathrm{df}}^{2}=0.097, \mathrm{p}=0.755$ \\
\hline Mechanism & & & $\chi_{5 \mathrm{df}}^{2}=3.190, \mathrm{p}=0.671$ \\
\hline FFH & $27.78 \%$ & $28.57 \%$ & \\
\hline MVA & $17.59 \%$ & $14.29 \%$ & \\
\hline Assault & $20.37 \%$ & $21.43 \%$ & \\
\hline Bike & $12.04 \%$ & $14.29 \%$ & \\
\hline FFOH & $12.04 \%$ & $0.00 \%$ & \\
\hline Peds v. car & $10.19 \%$ & $21.43 \%$ & \\
\hline ЕTOH (\% yes) & $28.57 \%$ & $42.57 \%$ & $\chi_{1 \mathrm{df}}^{2}=0.998, \mathrm{p}=0.318$ \\
\hline Antiplatelets (\% yes) & $0.00 \%$ & $4.21 \%$ & $\chi_{1 \mathrm{df}}^{2}=0.568, \mathrm{p}=0.451$ \\
\hline Coag abn & $46.15 \%$ & $15.84 \%$ & $\chi_{1 \mathrm{df}}^{2}=6.7951, \mathrm{p}=0.009^{*}$ \\
\hline Side (\% right) & $42.86 \%$ & $58.18 \%$ & $\chi_{1 \mathrm{df}}^{2}=1.186, p=0.276$ \\
\hline Location & & & $\chi_{4 \mathrm{df}}^{2}=1.572 ; \mathrm{p}=0.814$ \\
\hline $\mathbf{F}$ & $35.71 \%$ & $30.63 \%$ & \\
\hline $\mathbf{O}$ & $0.00 \%$ & $8.11 \%$ & \\
\hline $\mathbf{P}$ & $14.29 \%$ & $11.71 \%$ & \\
\hline PF & $0.00 \%$ & $1.80 \%$ & \\
\hline $\mathbf{T}$ & $50.00 \%$ & $47.75 \%$ & \\
\hline EDH volume (mean $\pm S D) \mathrm{cm}^{3}$ & $13.251 .3 \pm 13.558 .7$ & $9.348 .1 \pm 15.608 .2$ & $\mathrm{z}(\mathrm{MW})=1.354, \mathrm{p}=0.176$ \\
\hline Shift $($ mean \pm SD)mm & $0.46 \pm 1.08$ & $0.34 \pm 1.23$ & $\mathrm{z}(\mathrm{MW})=0.278, \mathrm{p}=0.781$ \\
\hline Related fracture & $85.7 \%$ & $70.3 \%$ & $\chi 21 \mathrm{df}=1.471, \mathrm{p}=0.225$ \\
\hline Depressed fracture & $14.3 \%$ & $4.5 \%$ & $\chi 21 \mathrm{df}=2.250, \mathrm{p}=0.134$ \\
\hline
\end{tabular}

Coag abn = coagulation abnormality, FFH = fall from height, FFOH = Fall from own height, GCS = Glasgow Coma Scale, ISS = Injury severity scale, LOC: Loss of consciousness, MVA $=$ Motor vehicle accident, ped vs car $=$ pedestrian versus car, $\mathrm{F}=$ frontal, $\mathrm{O}=$ occipital, $\mathrm{P}=$ Parietal, $\mathrm{PF}=$ parietofrontal, $\mathrm{T}=$ Temporal $\mathrm{ETOH}=$ alcohol abuse, $\mathrm{EDH}=$ epidural hematoma, $\mathrm{mm}=$ millimeters, $\mathrm{SD}=$ standard deviation, $*$ Statistically significant. 
Table 4: Results of the logistic regression predicting the event of surgery

\begin{tabular}{l|c|c|c|c|c|c}
\hline Surgery & Odds ratio & Standard error & $\mathbf{z}$ & P > |z| & \multicolumn{2}{|c}{ [95\% Confidence Interval] } \\
\hline Age & 0.9403547 & 0.0160745 & -3.60 & 0.000 & 0.9093712 & 0.9723937 \\
\hline EDH volume & 1.000035 & 0.0000152 & 2.32 & 0.020 & 1.000005 & 1.000065 \\
\hline Coagulopathy & 6.122418 & 4.313968 & 2.57 & 0.010 & 1.538689 & 24.361 \\
\hline Constant & 0.3813521 & 0.2346291 & -1.57 & 0.117 & 0.1141877 & 1.273599 \\
\hline
\end{tabular}

EDH: Epidural hematoma

using the three variables in the logistic regression, the sensitivity of the predictive model is $77 \%$ and the specificity is $80 \%$.

\section{Outcome}

Seven patients $(5.6 \%)$ died and a small proportion of subjects had severe disability (7.2\%). The majority of the sample $(87.2 \%)$ had a good recovery (GOSE between 5 and 7) early in evolution. Table 5 gives the distribution of the GOSE scores.

Having progression of the EDH was not associated $\left(\chi_{\mathrm{KW} 1 \mathrm{df}}^{2}=0.318, \mathrm{p}=0.5730\right)$ with a better or worse outcome (GOSE score). Even when controlling for age, coagulation abnormality and volume of the lesion, having EDHP was not a significant predictor of the outcome in an ordinal logistic regression $(\mathrm{OR}=0.644, \mathrm{p}=0.604)$.

\section{DiscuSSION}

This study has demonstrated that, contrary to common belief, the majority of traumatic EDH are not surgical emergencies with $75 \%$ of the cases initially treated conservatively. Furthermore, even when accounting for EDHP, two thirds of the EDH patients never required surgery. The main factors leading to EDHP found in this study were a younger age and coagulation abnormalities during the first 24 hours after presentation.

\section{Risk factors for EDHP}

The causes of EDHP have not been well studied. A recent randomized control trial $(\mathrm{RCT})^{13}$ examined the role of routine

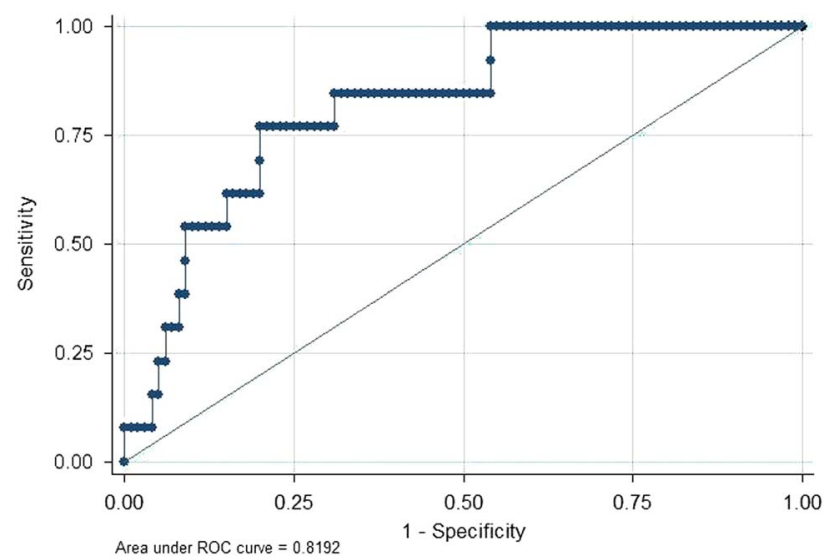

Figure 3: Receiver operating characteristic (ROC) curve of the prediction of surgery using the three variables (age, abnormal coagulation and hematoma volume) model. The total number of patient is 113 as coagulation as all three variables were known in 113 patients. serial CT scans in TBI and reported that 79 patients (46.2\% of the sample) had progression of TBI, but only ten of these 79 had EDH (7.9\%). Their sample also included delayed onset of hematomas. The latter should be better considered a different category ${ }^{12,17}$ and is outside the spectrum of our study. Risk factors for all hematomas progression were: higher D-dimer concentration, lower GCS on presentation, higher INR and to a lesser extent, shorter time lapse between trauma onset and initial CT. The finding of abnormality in coagulation profile correlates with our study. Bhau et $\mathrm{al}^{18}$ quoted a rate of $25 \%$ of patients who failed conservative treatment out of 89 patients but also did not differentiate EDHP from delayed onset EDH and reported no statistical analysis of potential risk factors for progression. A prospective series ${ }^{9}$ of 80 EDH patients of volume $<30 \mathrm{ml}$ treated conservatively concluded that in the five patients $(6.25 \%)$ who developed EDHP, the only significant association was temporal location. This could be overestimated because of the smaller number and exclusively temporally located cases of EDHP. Sullivan et al, ${ }^{12}$ in a retrospective study of 160 patients treated conservatively, found only higher revised trauma score (implying mild multisystem injury) to be significantly correlated to EDHP. In our study, ISS had no correlation to EDHP. Another small retrospective study ${ }^{19}$ reported 7 of 22 patients developed EDHP. Initial CT $<6$ hours from onset of trauma and skull fractures traversing major vascular structures were significant risk factors in that study. Injury to first CT time lapse was not investigated in our study. The significant correlation with younger age in our study is a new finding, yet it is not surprising. Indeed, it could be explained by the fact that, in older people, dura matter is more adherent to the internal table of the skull, leaving a faster tamponade effect and less potential epidural space in which the EDH may accumulate. Why it was not picked

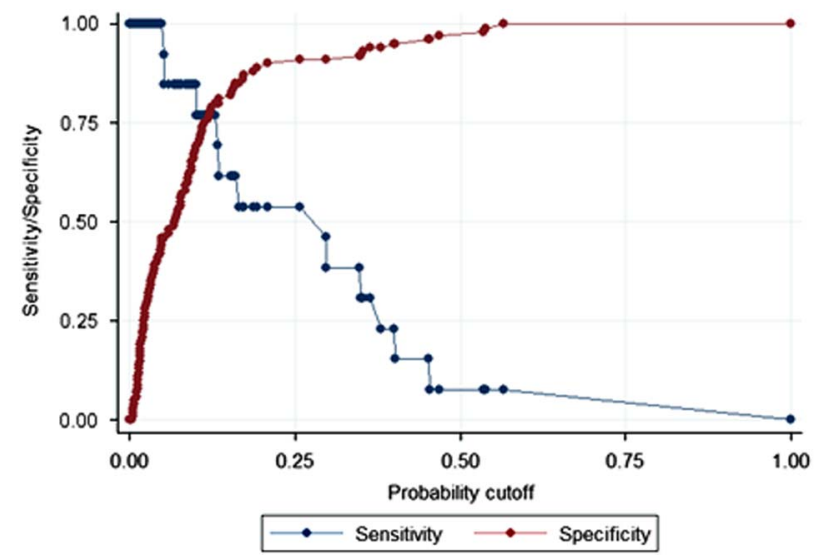

Figure 4: Sensitivity and specificity plot according to the probability of surgery. 
Table 5: Frequency of GOS scores $(n=125)$

\begin{tabular}{l|c|c}
\hline GOS & Frequency & Percent \\
\hline 1 & 7 & 5.6 \\
\hline 3 & 3 & 2.4 \\
\hline 4 & 6 & 4.8 \\
\hline 5 & 34 & 27.2 \\
\hline 6 & 66 & 52.8 \\
\hline 7 & 9 & 7.2 \\
\hline
\end{tabular}

GOS $=$ Glasgow Outcome Scale score

up in previous studies is not clear but one possible reason might be that our study includes patients of all ages, with a wide range of distribution and not only younger people. Finally, the volume of the hematoma was not a predictor of progression in our study, nor was it in any of the other studies. This is likely due to the fact that all hematomas treated conservatively were of small size.

\section{Timing of follow up CT scans}

The literature is not in favor of routine follow up CTs in mild TBI, as a recent meta-analysis ${ }^{20}$ revealed, but does recommend it for moderate and severe TBI. The question of optimal timing for follow up CTs remains, however, unanswered. ${ }^{13,21-23}$ In their RCT, Ding et al. ${ }^{13}$ performed serial follow up CTs, scheduled as follows: 6-8h, 20-22h, 48h and seven days for one TBI group and only when neurologically indicated for the controls. This resulted in significantly shorter stay in intensive care and total hospital stay, better GCS at discharge, and less spending among patients who developed progression of injury in the intervention arm. They recommended restricting routine CTs to patients with moderate or severe TBI. Another prospective cohort of mild TBI reported that hospital stay is reduced if CT scans were done only when clinically dictated. ${ }^{21}$ Figget et al. ${ }^{24}$ found, in a retrospective series, that repeat CT scan after 24-48 h doesn't change the management of severe nonsurgical TBI. Our study shows that most EDH patients treated conservatively according to the BTF guidelines had mild TBI. Most of our EDHP cases with initial mild TBI were diagnosed for progression on planned follow up scans. This may suggest that EDH should be considered a different subcategory of mild TBI in terms of necessity for routine serial CT scans follow up.

\section{Time interval for EDHP}

Progression of initially non-surgical EDH mostly occurs within the first $24 \mathrm{~h}$, less likely within $48 \mathrm{~h}$ and rarely beyond that. However, it did not occur before at least five hours. As identifying the actual injury time cannot be verified in many trauma cases, we supposed that the time elapsed from the initial CT was more practical. The Ding et $\mathrm{al}^{13} \mathrm{RCT}$ reported that $80 \%$ of patients (56 out of 70) complicated with progression of TBI did so within $24 \mathrm{~h}$ and the remaining $20 \%$ were delayed $24-48 \mathrm{~h}$. Epidural hematoma, non-operatively treated in accordance with the guidelines, in a prospective non-controlled study, ${ }^{11}$ have shown EDHP in $10 \%$ of patients, occurring within $12 \mathrm{~h}$ in 6 out of 70 patients and $24 \mathrm{~h}$ in 1 patient. However, they excluded another patient who developed EDHP after four days. In their larger study, Sullivan et al. ${ }^{12}$ had all EDHP diagnosed within $36 \mathrm{~h}$ interval from trauma onset and mean of $5.3 \mathrm{~h}$ from the initial CT scan. The smaller study of Knuckey et al. ${ }^{19}$ mentioned a mean time for EDHP of 2.7 days after admission (range of 1-10 days) in 7 of 22 patients. The critical period in their opinion was the first $24 \mathrm{~h}$ (71\% of EDHP in their sample). Our EDHP events ranged from 5 to $30 \mathrm{~h}$ (mean 13.85h) after the initial CT.

\section{Coagulopathy and EDHP}

Coagulopathy has been shown to cause progression of TBI. Recently, a retrospective $\operatorname{study}^{10}$ investigated the impact of coagulopathy on EDH outcomes of 85 patients, triaged in compliance with the BTF guidelines, into surgical and conservative groups. It showed a significant negative influence of coagulopathy on the outcomes of both groups but found no correlation with EDHP. This result is questionable when considering the smaller sample number and lack of multivariate analysis. There are variable data in the literature and different studies associated one or more of the following with TBI progression: Prothrombin time (PT) or INR, Partial thromboplastin time (PTT), thrombocytopenia, high fibrin degradation and low fibrinogen levels. ${ }^{25-30}$ Fewer other studies reported no association between coagulopathy and bleeding progression in TBI. ${ }^{31-33}$ This considerable variation is attributed to lack of consensus on TBI-coagulopathy definition, heterogeneity of patients involved, variable laboratory tests used in different studies and timing to perform these tests and CTs. ${ }^{34-35}$ The presence of hypodense areas within the epidural hematoma on CT scan is thought to be related to coagulopathy, ${ }^{36}$ yet its association with EDHP is lacking adequate investigations.

\section{TBI associated coagulopathy}

Nearly half of our EDHP patients had coagulopathy, despite the fact that none of the patients (one with missing data) were on anti-platelet or anticoagulation medication. This raises the suspicion of TBI-associated coagulopathy, which has an uncertain pathophysiology. ${ }^{34-35}$ The overall incidence of TBI-associated coagulopathy in a meta-analysis was $32.7 \%$ and was significantly associated with mortality and unfavorable outcome. ${ }^{37} \mathrm{~A}$ multicenter prospective study reported that within $6 \mathrm{~h}$ from injury, $36 \%$ of its TBI sample fulfilled the criteria for overt disseminated intravascular coagulopathy (DIC) which proved to have a significant correlation with hemorrhage progression. All other causes of coagulopathy were excluded in that study. ${ }^{38} \mathrm{~A}$ more recent multicenter study ${ }^{39}$ demonstrated that both delayed and early sustained coagulopathy in isolated TBI correlates with more abnormalities on initial CT, hematomas $>25 \mathrm{ml}$ and worse outcomes in comparison with early short-term coagulopathy.

\section{Outcome}

The cause of EDHP is supposedly a re-hemorrhage event or continuous slow bleeding. ${ }^{12,18}$ Brain Trauma Foundation guidelines for successful EDH conservative management states that: "An EDH less than $30 \mathrm{~cm}^{3}$ and with less than a $15-\mathrm{mm}$ thickness and with less than a 5-mm midline shift (MLS) in patients with a GCS score greater than 8 without focal deficit can be managed non-operatively with serial computed tomography (CT) scanning and close neurological observation in a neurosurgical center". 8 The safety of these guidelines for conservative treatment of $\mathrm{EDH}$ was recently tested in a prospective non- 
controlled study of 70 patients which showed its safety but emphasized the need for close observation and serial CT scans. ${ }^{11}$ Brain Trauma Foundation guidelines proved to be safe and provided good outcomes for EDH patients treated conservatively. Should EDHP develop, then timely surgical intervention can maintain similar outcomes to the successful conservatively treated counterparts, as this study and all other related studies have shown. ${ }^{10-12}$

The early outcome of our cohort was favorable for the great majority. A small number died or had severe disability. A poor outcome was not linked to EDH progression however, but rather to the patients' initial injury severity and older age.

Limitations of our study include its retrospective nature and a small number of patients with missing data. On the other hand, the research question was very specific and the sample number was adequate to perform statistical comparison and multivariate analysis. Another limitation of our study is that the outcome was measured systematically for all patients early in the evolution of the patients (at discharge from acute care hospital). While most of the patients already fell into the category of "good outcome", the long term outcome would likely be better still.

Furthermore, all patients with EDH were included in this study, and patients with concomitant injuries were included as well. The patients' outcome could therefore be influenced by the severity of the initial injury and not only by the EDH. The advantage of including patients with concomitant injuries in this study is that the results can be extrapolated to all patients with EDH and not only those with pure EDH, as the latter category does not in fact represent the majority of EDH seen in clinical practice.

\section{Conclusion}

Traumatic EDH can be successfully treated conservatively in the majority of cases. A small proportion of these non-surgical EDH will progress and require surgical evacuation. Increased vigilance is indicated for younger adults and those with coagulopathy. Routine follow up CT scans should be done, but the best time frame remains unclear. However, early detection of EDHP and urgent evacuation results in similar outcomes to patients with fully successful conservative management.

\section{Disclosures}

None of the authors have anything to disclose.

None of the authors have any competing financial interests.

\section{REFERENCES}

1. Bullock MR, Chesnut R, Ghajar J, et al. Surgical management of acute epidural hematomas. Neurosurgery. 2006;58(Suppl): S7-S15.

2. Cordobes F, Lobato RD, Rivas J, et al. Observations on 82 patients with extradural hematoma. Comparison of results before and after the advent of computerized tomography. J Neurosurg. 1981; 54:179-86.

3. Gupta S, Tandon SC, Mohanty S, Asthana S, Sharma S. Bilateral traumatic extradural haematomas: Report of 12 cases with a review of the literature. Clin Neurol Neurosurg. 1992;94:127-31.

4. Bricolo AP, Pasut LM. Extradural hematoma: toward zero mortality. A prospective study. Neurosurgery. 1984;14:8-12.

5. Cucciniello B, Martellotta N, Nigro D, Citro E. Conservative management of extradural haematomas. Acta Neurochir. 1993;120:47-52.

6. Kuday C, Uzan M, Hanci M. Statistical analysis of the factors affecting the outcome of extradural haematomas: 115 cases. Acta Neurochir. 1994;131:203-6.
7. Lee EJ, Hung YC, Wang LC, Chung KC, Chen HH. Factors influencing the functional outcome of patients with acute epidural hematomas: Analysis of 200 patients undergoing surgery. J Trauma. 1998;45:946-52.

8. van den Brink WA, Zwienenberg M, Zandee SM, van der Meer L, Maas AI, Avezaat CJ. The prognostic importance of the volume of traumatic epidural and subdural haematomas revisited. Acta Neurochir. 1999;141:509-14.

9. Bezircioğlu H, Erşahin Y, Demirçivi F, Yurt I, Dönertaş K, Tektaş S. Nonoperative treatment of acute extradural hematomas: analysis of 80 cases. J Trauma. 1996;41:696-8.

10. Mayr R, Troyer S, Kastenberger T, et al. The impact of coagulopathy on the outcome of traumatic epidural hematoma. Arch Orthop Trauma Surg. 2012;132:1445-50.

11. Salama MM, Eissa EM. Conservative Management of Extradural Hematoma: Experience with 70 Cases. Egyptian J Neurol Surgeons. 2010;25:185-94.

12. Sullivan TP, Jarvik JG, Cohen WA. Follow-up of conservatively managed epidural hematomas: Implications for timing of repeat CT. Am J Neuroradiol. 1999;20:107-13.

13. Ding J, Yuan F, Guo Y, et al. A prospective clinical study of routine repeat computed tomography (CT) after traumatic brain injury (TBI). Brain Inj. 2013;26:1211-6.

14. Petersen OF, Espersen JO. Extradural hematomas: measurement of size by volume summation on CT scanning. Neuroradiology. 1984;26:363-7.

15. Jennett B, Bond M. Assessment of outcome after severe brain damage: a practical scale. Lancet. 1975;1:480-4.

16. Jennett B, Snoek J, Bond MR. Disability after severe head injury: observations on the use of the Glasgow Outcome Scale. J Neurol Neurosurg Psychiatry.. 1981;44:285-93.

17. Domenicucci M, Signorini P, Strzelecki J, Delfini R. Delayed posttraumatic epidural hematoma. A review. Neurosurg Rev. 1995; 18:109-22.

18. Bhau KS, Bhau SS, Dhar S, Kachroo SL, Babu ML, Chrungoo RK. Traumatic extradural hematoma role of nonsurgical management and reasons for conversion. Indian J Surg. 2010;72:124-9.

19. Knuckey NW, Gelbard S, Epstein MH. The management of "asymptomatic" epidural hematomas. A prospective study. J Neurosurg. 1989;70(3):392-6.

20. Almenawer SA, Bogza I, Yarascavitch B, et al. The value of scheduled repeat cranial computed tomography after mild head injury: singlecenter series and meta-analysis. Neurosurgery. 2013;72:56-62.

21. AbdelFattah KR, Eastman AL, Aldy KN, et al. A prospective evaluation of the use of routine repeat cranial CT scans in patients with intracranial hemorrhage and GCS score of 13 to 15 . J Trauma Acute Care Surg. 2013;73:685-8.

22. Brown CV, Zada G, Salim A, et al. Indications for routine repeat head computed tomography (CT) stratified by severity of traumatic brain injur. J Trauma. 2007;62:1339-44.

23. Sifri ZC, Homnick A, Vaynman A, et al. A prospective evaluation of the value of repeat cranial computed tomography in patients with minimal head injury and an intracranial bleed. J Trauma. 2006;61:862-7.

24. Figg RE, Burry TS, Vander Kolk WE. Clinical efficacy of serial computed tomographic scanning in severe closed head injury patients. J Trauma. 2003;55:1061-4.

25. Allard CB, Scarpelini S, Rhind SG, et al. Abnormal coagulation tests are associated with progression of traumatic intracranial hemorrhage. J Trauma. 2009;67:959-67.

26. Kaufman HH, Moake JL, Olson JD, et al. Delayed and recurrent intracranial hematomas related to disseminated intravascular clotting and fibrinolysis in head injury. Neurosurgery. 1980; 7:445-9.

27. Kumura E, Sato M, Fukuda A, Takemoto Y, Tanaka S, Kohama A. Coagulation disorders following acute head injury. Acta Neurochir. 1987;85:23-8.

28. Oertel M, Kelly D, McArthur D, et al. Progressive hemorrhage after head trauma: predictors and consequences of the evolving injury. J Neurosurg. 2002;96:109-16.

29. Stein SC, Spettell C, Young G, Ross SE. Delayed and progressive brain injury in closed-head trauma: radiological demonstration. Neurosurgery. 1993;32:25-30. 
30. Stein SC, Young G, Talucci RC, Greenbaum BH, Ross SE. Delayed brain injury after head trauma: significance of coagulopathy. Neurosurgery. 1992;30:160-5.

31. Chang EF, Meeker M, Holland MC. Acute traumatic intraparenchymal hemorrhage: risk factors for progression in the early post-injury period. Neurosurgery. 2006;58:647-56.

32. Crone KR, Lee KS, Kelly DL Jr. Correlation of admission fibrin degradation products with outcome and respiratory failure in patients with severe head injury. Neurosurgery. 1987;21:532-6.

33. Sawada Y, Sadamitsu D, Sakamoto T, Ikemura K, Yoshioka T, Sugimoto T. Lack of correlation between delayed traumatic intracerebral haematoma and disseminated intravascular coagulation. J Neurol Neurosurg Psychiatry. 1984;47:1125-7.

34. Laroche M, Kutcher M, Huang MC, Cohen MJ, Manley GT. Coagulopathy after traumatic brain injury. Neurosurgery. 2012; 70:1334-45.
35. Zhang J, Jiang R, Liu L, Watkins T, Zhang F, Dong JF. Traumatic brain injury-associated coagulopathy. J Neurotrauma. 2012;29: 2597-2605.

36. Hamilton M, Wallace C. Nonoperative management of acute epidural hematoma diagnosed by CT: The neuroradiologist's role. Am J Neuroradiol. 1992;13:853-9.

37. Harhangi BS, Kompanje E, Leebeek FW, Maas AI. Coagulation disorders after traumatic brain injury. Acta Neurochir. 2008; 150:165-75.

38. Sun Y, Wang J, Wu X, et al. Validating the incidence of coagulopathy and disseminated intravascular coagulation in patients with traumatic brain injury-analysis of 242 cases. Br J Neurosurg. 2011;25:363-8.

39. Franschman G, Boer C, Andriessen TM, et al. Multicenter evaluation of the course of coagulopathy in patients with isolated traumatic brain injury: relation to CT characteristics and outcome. J Neurotrauma. 2012;29:128-36. 